\title{
A conquista do trabalho e o direito ao ócio
}

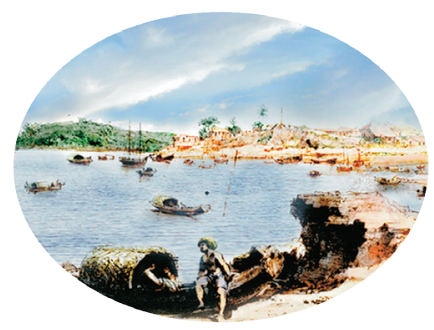

Victor Leandro da Silva* Iraildes Caldas Torres**

\section{Resumo}

O conceito de trabalho passou por inúmeras mudanças até chegar às feições pelas quais ele é conhecido nos dias de hoje, como um direito social que assiste a cada indivíduo. Entretanto, essas transformações também conduziram a uma discussão acerca de sua importância, a ponto de ser possível vislumbrar uma sociedade em que este não ocupa mais uma função central dentro das relações humanas, o que leva a questionamentos sobre o valor do trabalho e o lugar do ócio dentro da sociedade contemporânea.

Palavras-chave: Trabalho; sociedade; ócio.

\begin{abstract}
The concept of work has gone through many changes until the features for which he is known today as a social right which assists the individual. However, these changes also led to a discussion of its importance as to be able to envision a society in which it no longer occupies a central role in human relationships, which leads to questions about the value of work and place of leisure within contemporary society.
\end{abstract}

Keywords: Labor; society; leisure.

\footnotetext{
* Licenciado em Filosofia pela UFAM. Mestrando do Programa de Pós-Graduação Sociedade e Cultura na Amazônia da mesma instituição. E-mail: viktorleandro@hotmail.com

** Professora da Universidade Federal do Amazonas (UFAM). Possui doutorado em Ciências Sociais/Antropologia pela Pontifícia Universidade Católica de São Paulo (PUC/SP). E-mail: iraildes.caldas@gmail.com
} 


\section{Introdução}

O trabalho passou por constantes evoluções até ocupar a posição que ocupa dentro da organização social. Nesse caminho, ele assumiu vários papéis, os quais o conduziram para uma posição privilegiada, que é a de um componente essencial para a vida e o progresso da humanidade.

Contudo, tal posição também criou um contraponto, que foi a supressão de outras atividades importantes ao homem, e, principalmente, do ócio, que foi historicamente classificado de modo pejorativo, como um símbolo de má índole e de estagnação.

Assim, a pergunta que prepondera é se, numa sociedade totalmente voltada para o trabalho, ainda existe espaço para o tempo livre. Tais indagações levam a pensar a respeito de uma outra questão, que é sobre a possibilidade de se criar um modelo social que não seja pautado exclusivamente no trabalho, e que abra espaço para outras manifestações humanas.

Porém, para que se chegue a essas elucubrações, é preciso que se perceba a progressão histórica do ideal de trabalho, a fim de que se possa refletir sobre seus desdobramentos dentro da ordem capitalista vigente no mundo contemporâneo.

\section{Evolução do conceito de trabalho}

O conceito de trabalho passou por inúmeras transformações até atingir a delimitação na qual está inserido na contemporaneidade, como direito social e ponto fundante de toda a atividade humana.

Entre os gregos, o trabalho era tido como uma atividade inferior, "um mal físico necessário”(MILLS, 1969, p. 233), que deveria ser evitado a qualquer custo. Também entre os hebreus, o trabalho possuía um sentido de expiação dos pecados, em contraposição ao ócio abençoado da vida eterna.

Vale lembrar que, para essas civilizações, o trabalho ainda não era associado à atividade intelectual. Esta não era considerada um ofício, sendo 
um atributo destinado aos membros das classes mais favorecidas. Assim, quando se faz referência, entre os gregos, à ideia de que o trabalho é um mal a ser evitado, está-se levando em conta somente a atividade que pede um esforço físico para sua realização, que requeira movimento e dispêndio de energia. Desse modo, o labor intelectual permanece fora dessa perspectiva.

No cristianismo, a visão sobre o trabalho também não se afastava muito do que pensavam gregos e hebreus. Condenação imputada ao homem por razão de sua natureza pecaminosa, o trabalho era, na concepção cristã, uma atividade indigna. Contudo, ele também possuía uma função doutrinadora, pois afastava o homem dos maus pensamentos e também funcionava como uma espécie de purificação, por estar ligado à caridade. Ainda assim, era visto de forma vexatória e depreciativa, devendo ser suportado como um martírio.

Foi somente com Lutero que o trabalho passou a ser pensado a partir de um novo conceito. Segundo ele, o trabalho tinha uma função centralizadora na vida humana, embora fosse uma consequência da queda do homem pelo pecado. Para Lutero, o trabalho era visto como uma forma de servir a Deus, e de afastar-se do pecado. A noção de predestinação, preconizada por Calvino, serviu para acentuar ainda mais o novo posicionamento cristão acerca desse tipo de atividade humana.

A partir daí, o trabalho passou para uma nova categoria, não mais sendo um exercício humilhante ou expiatório, mas um ofício divino, uma realização da vontade de Deus e uma forma de dignificação do homem. Depois disso, as análises feitas acerca do trabalho procuraram abordá-lo de modo afastado da Teologia, situando-o no campo das relações econômicas e sociais, adquirindo com isso as feições que o moldariam dentro da modernidade.

Com o renascimento, o trabalho ganhou um novo atributo. Este se caracterizaria agora como um exercício da razão, e, por isso, uma forma de arte. Já os liberais o consideravam como a origem de toda a riqueza, do valor econômico, posto que era através dele que se poderia aferir o nível de acúmulo de bens pelas nações.

Mas, segundo Mills, foi com Marx que o trabalho ganhou um significado essencial para a vida humana. Já antes dele, outras teorias apontavam o trabalho como uma atividade que não deveria ter em vista apenas o lucro e o acúmulo de capital. Porém, com Marx, esta teleologia do trabalho tornou- 
se amplamente combatida, pelo fato de constituir-se no cerne de regimes econômicos opressores, como o capitalismo e também o antigo sistema feudal.

Para Marx, o trabalho é fundamental para o desenvolvimento humano. É através dele que agilizamos nossos membros superiores, e adquirimos novas faculdades para o raciocínio. É também por seu intermédio que solidificamos nossas relações sociais, formando a sociedade.

Desse modo, o trabalho, de acordo com Marx, não pode ser exercido como forma de dominação e tampouco de animalização do homem, posto que sua função é justamente contrária a isso. Para tanto, é preciso que se crie um sistema econômico que omita os mecanismos de dominação das forças produtivas humanas, e impeça o acúmulo de riqueza por parte de um grupo em detrimento da maioria.

O trabalho, considera Marx, não é uma punição, nem tampouco um martírio ou meio de opressão. Logo, é preciso que se estabeleça uma forma de organização político-econômica que assegure o direito ao trabalho a cada indivíduo, a qual, para ele, não pode ser o capitalismo, já que este é imanentemente produtor de alienação, pois retira do operário aquilo que produz e passa-o à mão do proprietário da fábrica.

Assim, a noção de trabalho como direito social passará a ficar bastante relacionada à teoria marxista. Contudo, seus efeitos não se restringiram somente aos estados que assumiram um governo comunista, e estendeu-se também à sociedade do capital.

Nas nações capitalistas, a despeito da coibição praticada por estas contra os movimentos de emancipação do trabalhador, ocorreram diversos eventos que ajudaram a redefinir o conceito de trabalho. Surgiram os sindicatos. Os trabalhadores passaram a exigir mais direitos, o próprio capitalismo sentiu a necessidade de modificar sua relação com o proletariado, a fim de garantir sua sobrevivência. Com isso, o trabalho, mesmo partindo de uma concepção diferente, aproximou-se do conceito defendido por Marx. Ainda assim, a ideia de aliar capitalismo e direitos do trabalhador permaneceu contraditória, em conta dos próprios fundamentos sob os quais o capitalismo está sedimentado.

Foi Webber quem primeiro analisou as origens do processo de construção da essência do capitalismo, a qual ele imaginou estar bastante atrelada ao 
pensamento cristão expresso por meio da ética protestante. Ele toma como base para este raciocínio a constatação de que em sua época:

Os líderes do mundo dos negócios e proprietários do capital, assim como dos níveis mais altos da mão de obra qualificada, principalmente o pessoal técnica comercialmente especializado das modernas empresas, serem preponderantemente protestantes. Isso não ocorre apenas quando a diferença de religião coincide com uma de nacionalidade, e, em consequência, com uma de desenvolvimento cultural (WEBBER, 1996, p. 19).

Para Webber, o fato de que os protestantes eram os grandes detentores do capital em sua época, em detrimento dos trabalhadores católicos, não era simples coincidência, ou somente o resultado da concentração de protestantes em países mais avançados industrialmente. Segundo ele, havia uma estreita ligação entre o capitalismo e a fé de matriz luterana e calvinista, que tinha uma afinidade ética muito maior com a crescente ordem econômica do que o catolicismo, o qual, asseverava Webber, tinha ambições bem mais limitadas no que diz respeito ao trabalho. O católico voltava-se mais para questões espirituais, para uma possível felicidade além-mundo, enquanto que o trabalho deveria apenas servir para a obtenção dos meios básicos de subsistência, sem aspirar a um acúmulo maior de bens.

Para o protestante, o trabalho, como uma das formas de atender aos desígnios divinos, era estimulado, assim como também o acúmulo. O ethos protestante era sobretudo voltado para o fazer prático, para o labor, sendo que o indivíduo que não trabalhasse ou trabalhasse pouco era malvisto e tomado como alguém de pouco valor.

Como consequência disso, Webber observa que a grande maioria dos profissionais especializados em cargos de relevância na sua época eram protestantes. Também a procura destes pelos cursos nas universidades que visem atender às demandas do mercado de trabalho é bem maior do que entre os católicos, que optam por estudos que estejam mais voltados para as humanidades. Assim, os valores protestantes parecem estar muito mais voltados para uma cultura do trabalho e da indústria que os dos católicos, que parecem preocupar-se mais com problemas como a felicidade e o bem-viver. 
Dessa forma, Webber irá propor que o capitalismo, em sua estrutura fundamental, está intimamente relacionado à ética que foi perpetrada pelo protestantismo, a qual, contrariamente aos valores católicos, está bastante ligada a questões pragmáticas, que exigem uma ação que traga resultados efetivos, uma doutrina da práxis humana, que deve visar principalmente ao progresso e ao bem-estar material do homem. Logo, é dentro do protestantismo que a sociedade capitalista irá encontrar os valores constitutivos de sua origem, tais como a valorização do trabalho, o apreço pelo acúmulo de bens, ou a necessidade de ocupar o tempo por meio de atividades que sejam lucrativas.

Com isso, segundo Webber, "ganhar dinheiro dentro da ordem econômica moderna é, enquanto for feito legalmente, o resultado e a expressão da virtude e da eficiência em uma vocação" (WEBBER, 1996, p. 33). Portanto, a ética protestante atua como legitimadora do ideal capitalista, tornando-se desse modo o elemento moral normativo de sua gênese.

Diante disso, o capitalismo irá aparecer como tendo origem na religião protestante, nos preceitos éticos do protestantismo que se aliaram à moral burguesa, ajudando a construir a perspectiva do trabalho da maneira como ela é tomada contemporaneamente.

E, para Mills, o trabalho contemporâneo está marcado pela alienação, a qual irá dar-se por diversos motivos. Segundo ele, a forma de trabalho que mais envolvia o trabalhador e seu produto, o artesanato, tornou-se uma atividade menor, concebida agora apenas como um passatempo ou sustento de poucos indivíduos ou comunidades isoladas, isso graças ao advento da indústria. Outro aspecto negativo desse fenômeno é que com ele houve uma cisão entre trabalho e lazer, já que ambas as atividades se uniam por meio do ofício do artesão.

Além disso, a saída do homem da zona rural para a cidade provocou maior dependência deste das regras estabelecidas pela sociedade industrial, que tenta cada vez mais separar o homem da mercadoria que fabrica. A grande quantidade de trabalhadores disponíveis também implica que pessoas exerçam funções que estão aquém de suas capacidades, sem aproveitar o máximo de seu potencial. Tudo isso faz com que o trabalho aos poucos vá se esvaindo em seu sentido, e acabe tornando-se um simples meio de obter salário, sem qualquer relação mais significativa com o sujeito que o exerce. 
Um outro fator que contribuiu decisivamente para a alienação do operário foi o aparecimento da linha de montagem. Anteriormente, o indivíduo participava de todo o processo de produção da mercadoria, desde sua idealização até a confecção final do produto. Já com a linha de montagem, o trabalhador passou a especializar-se em uma função apenas, sem atentar mais para o que ocorre antes ou depois de sua tarefa. Assim, ele se viu separado do objeto que produziu, simplesmente por não saber de que maneira ele foi feito.

O resultado disso é que, para o funcionário da fábrica, a mercadoria feita torna-se estranha a ele, perdendo desse modo o seu significado enquanto objetivo final de seu ofício. E o próprio funcionário, para o patrão, não é mais aquele responsável pela geração de sua riqueza. Esta cabe exclusivamente ao proprietário e suas máquinas.

Como desdobramento dessa condição, tem lugar a figura dos colarinhosbrancos. Estes, já totalmente afastados da propriedade e da razão operante sobre a produção, são treinados para executarem tarefas de forma mecânica, sob o comando de um gerente. Não possuem voz ou autonomia para agir segundo seu processo crítico, e tomam decisões mediante os comandos daqueles que ocupam cargos superiores aos seus. São profissionais que estão bastante próximos, isso se não a alcançaram, da manipulação plena dentro do mundo do trabalho. São indivíduos que caminham a passos largos rumo à alienação totalizante.

Dentro dessa conjuntura, o trabalho na contemporaneidade, longe de se configurar numa junção entre esforço e lazer, tornou-se uma atividade penosa e sem significado, desprovida de um valor intrínseco, e passou a ser praticado visando a dois objetivos que lhe são exteriores, o ganho financeiro e o status social.

No que diz respeito ao lucro, Mills afirma que "as motivações econômicas constituem atualmente o único fundamento do trabalho"(p. 248). Portanto, o trabalho é visto exclusivamente como um meio de se obter dinheiro, e terá mais valor conforme aumentar o ganho que se poderá obter através dele. Com isso, a lógica operacional do trabalho passou a ser a do acúmulo financeiro, sendo este o objeto principal das reivindicações dos trabalhadores, em detrimento de outras conquistas. 
Quanto ao status social, assim como a geração de riqueza, serve como compensação pela ausência de satisfação com o trabalho, e aparece intimamente relacionado ao lucro. O emprego numa grande firma, os elevados salários, a ocupação de cargos importantes na hierarquia de uma empresa, são componentes que proporcionam prazer ao funcionário, pois se apresentam a ele como elementos valorativos de suas qualidades, de sua capacidade em ser útil dentro da função que pratica.

Porém, mesmo esses novos objetivos do trabalho não são suficientes para aplacar a insatisfação dos empregados. Eles continuam a se sentir pouco gratificados com a ocupação que exercem, e não aceitam passivamente a condição alienante em que se encontram.

Com isso, a procura por encontrar meios que amenizem os impactos do trabalho sobre a vida do indivíduo se tornou cada vez maior. Os trabalhadores passaram a reivindicar cada vez mais tempo livre para o lazer, e o trabalho passou a ser medido pelo acesso ao lazer que proporciona.

Criou-se, assim, a indústria do entretenimento. Seu objetivo é o de oferecer mecanismos de fuga à alienação e ao estado opressor do regime de produção capitalista.

Contudo, esta indústria de divertimento, que está aliada à indústria cultural, não deixa de estar atrelada ideologicamente aos ditames do capitalismo, e participa com ela do processo de alienação. Seu papel é oferecer, contra a vacuidade do trabalho, o vazio dos divertimentos passivos e desprovidos de função criadora, contribuindo desse modo para a perpetuação do ciclo vicioso entre trabalho alienante e entretenimento fútil, tal como bem mostra o exemplo referido por Adorno (2002): "Pato Donald mostra nos desenhos animados como os infelizes são espancados na realidade, para que os espectadores se habituem com o procedimento" (p. 33). Neste exemplo, nota-se que o espectador, que no caso é o filho do operário, é desde cedo treinado para o martírio que o trabalho lhe reserva.

Dessa forma, a função principal do entretenimento é fornecer meios de pacificação das massas, oferecendo passatempos estéreis e sem significado, com a única finalidade de acalmar a mente oprimida do trabalhador, ao mesmo tempo em que ratifica, através da exaltação da figura de ricos e famosos e da 
defesa velada do regime de trabalho opressor, o Estado em que se organiza a sociedade capitalista vigente.

Logo, não é com o simples aumento do tempo disponível para o lazer que o operário se verá livre da condição alienante que o trabalho lhe impõe. $\mathrm{Na}$ verdade, a procura por lazer somente acentua a já evidente insatisfação com ciclo de suas atividades rotineiras, a qual a indústria do entretenimento tem por objetivo amenizar, ao passo que também solidifica no indivíduo sua relação de dependência para com o trabalho. Assim, a monotonia permanece, tornando ainda mais claro o vazio das atividades do homem contemporâneo.

\section{Um novo paradigma}

A alienação do indivíduo perante o trabalho faz com que se torne preciso discutir a elaboração de um novo modelo de organização social, que garanta ao homem um significado para suas atividades. Por isso, os debates acerca da importância do trabalho têm sido cada vez mais constantes.

Porém, este novo sistema que se procura elaborar esbarra nas condições materiais estabelecidas, as quais levam os teóricos a pensar numa solução radical para os problemas que mundo do trabalho tem apresentado.

Não se trata apenas de buscar alternativas que visem à redução dos impactos resultantes das relações de trabalho. Isso éalgo que já foi experimentado com o aumento das ofertas de lazer, e o resultado foi um agravamento das condições já existentes. O que muitos estudiosos têm pensado é que o trabalho talvez não seja o único centro possível das ações humanas, e que seja viável usar um novo arquétipo que possa dar novamente sentido ao agir do homem.

Nesse contexto, surgem como proposta as ideias do filósofo inglês Bertrand Russell, que defende uma sociedade não mais centralizada no trabalho, mas que tenha no ócio os elementos orientadores de seu situar-se no mundo.

Em "Elogio ao ócio" (2002), Russell irá discorrer sobre as possibilidades de aventar um modelo de organização social focalizado no lazer, conferindo ao trabalho a simples função de assegurar os meios de subsistência, sem qualquer interferência além deste âmbito.

Para Russell, a crença historicamente estabelecida de que o trabalho é o 
ícone maior da virtude humana não é válida, e deve ser substituída por uma existência pautada no ócio. Contudo, Russell deixa claro que não está tratando de qualquer tipo de ociosidade, como a dos proprietários de terra, para os quais o

ócio só é possível devido ao trabalho de outros e, na verdade, a sua aspiração a um ócio confortável é, historicamente, a origem de todo o evangelho do trabalho. A última coisa que essa gente jamais deseja é que outros seguissem o seu exemplo (RUSSELL, 2002, p. 26).

Assim, o ócio aristocrático, ou do industrial, que é conquistado à custa da usurpação do tempo livre de outros, não tem valor. Para Russell, só interessa o ócio daqueles que produzem, que conquistam o direito ao tempo livre por seus próprios meios.

Russell afirma que a defesa da concepção do trabalho como virtude é um artifício criado pelas classes dominantes para legitimar o regime de escravidão a que submetem o povo. Justificar o trabalho extenuante e opressivo via argumentos é bem mais simples do que usar a força, contudo, Russell considera que, embora isso possa ter sido útil à humanidade por determinadas razões, com o advento da revolução industrial e o uso das máquinas, esta ditadura do trabalho tornou-se absolutamente desnecessária. Como exemplo, Russell mostra o da Primeira Guerra Mundial, em que diversas pessoas foram deslocadas de suas atividades laborais para servir como agentes militares, sem que com isso o bem-estar social fosse afetado.

Logo, a proposta de Russell é que o ócio, outrora privilégio de uma camada mínima da população, seja democratizado, e passe a ser um direito de todos e não apenas dos ricos.

Daí em diante, ele propõe que, com a ajuda da automatização, crie-se uma sociedade centrada no lazer e não no trabalho. Ora, não faz sentido, considera ele, que numa fábrica onde se produz a quantidade suficiente de um produto numa jornada de quatro horas diárias, trabalhe-se oito, lançando no mercado uma quantidade bem maior da mercadoria do que este necessita, gerando um excedente que depois se converterá em menos postos de trabalho. Essa é uma lógica que atende apenas aos interesses do patrão, e é fruto da 
cultuação do trabalho que escraviza o homem, ao mesmo tempo em que ajuda a introduzi-lo na miséria.

Diante disso, Russell sugere que o trabalhador tenha uma jornada de trabalho de quatro horas por dia. Assim, haveria emprego para todos, e o bemestar social seria assegurado. Além disso, o tempo de lazer estaria garantido.

Desse modo, a questão a ser feita é se o tempo de ócio disponibilizado não implicaria tédio, ou se este seria usado em divertimentos vazios e pouco edificantes. Porém, novamente é necessário pensar que a mudança proposta por Russell é de paradigma, e não apenas de hábitos sociais. Numa sociedade baseada no lazer, o tempo livre teria uma função criadora, ao contrário do que ocorre no mundo capitalista vigente, em que o objetivo do ócio é a inércia mental. Só que, para que haja essa mudança, a reforma do pensamento precisa ser radical, pois, como o próprio Russell afirma, "um homem que toda a sua vida trabalhou longas horas irá se sentir entediado se ficar ocioso de repente" (RUSSELL, 2002, p. 30). Portanto, é necessário que se forme uma educação para o ócio, que ressalte as benesses desse regime, as quais Russell procura expor em seu texto.

A primeira delas tem comprovação histórica. Boa parte das grandes realizações humanas foi realizada mediante a utilização de um vasto tempo livre. Assim, o ócio é o espaço onde podem configurar-se as criações, porém, esse exemplo histórico não é universalmente válido, já que este ócio foi obtido por meio da supressão do lazer de muitos.

Outro argumento é que o ócio permite que o indivíduo se dedique a atividades que sejam verdadeiramente enriquecedoras, e neste ponto entra a proposta de Russell de uma sociedade do lazer. Se um trabalhador tem uma carga horária de quatro horas diárias, assegurando com isso o seu sustento e o dos que dele dependem, ele pode aproveitar o restante de seu dia não em frivolidades, mas em diversões que trouxessem benefícios para a formação do indivíduo. E aqui o autor não se refere somente a atividades intelectualizadas. As danças populares são um exemplo de divertimento prazeroso, ativo e de valor cultural, mas que não são mais praticadas em função do trabalho que consome as energias humanas e leva os trabalhadores a desfrutar de divertimentos passivos, dos quais ele é mero espectador. Desse modo, o tempo 
livre seria aproveitado na fruição das artes, na prática desportiva e na obtenção do conhecimento, trazendo inegáveis benefícios para todos.

Assim, o autor traça o seu modelo de civilização, baseada no bom aproveitamento das horas livres e numa jornada mínima de quatro horas para o trabalho. Nesse tipo de organização, Russell afirma que:

acima de tudo haverá felicidade e alegria de viver, em vez de nervos em frangalhos, fadiga e má digestão. $\mathrm{O}$ trabalho exigido será suficiente para tornar agradável o lazer, mas não levará ninguém a exaustão. $\mathrm{E}$ como não estarão cansadas nas horas de folga, as pessoas deixarão de buscar diversões exclusivamente passivas e monótonas. Uma pequena parcela dedicará, com certeza, o tempo não gasto na ocupação profissional a atividades de alguma utilidade pública, e, como não dependerão dessas atividades para a sua sobrevivência, não terão a originalidade tolhida e nem necessidade de se amoldarem aos padrões estabelecidos pelos velhos mestres (RUSSEL, 2002, p. 35).

E ele diz ainda que "o gosto pela guerra desaparecerá, em parte por esse motivo, em parte porque a guerra implicará em trabalho longo e penoso para todos" (RUSSELL, 2002, p. 35).

É claro que se pode questionar as prospecções feitas por Russell, classificando-as como utópicas, mas é preciso que se lembre de que o modelo proposto por ele já existe e é praticado pelas camadas mais abastadas da sociedade, que desfrutam de prazer e educação num quase ilimitado tempo livre, ao passo que condenam o ócio dos outros e vivem às custas do esforço dos trabalhadores. O que falta, segundo Russell, é distribuir este direito equitativamente, para que todos se livrem da opressão do trabalho e possam fruir os prazeres que somente o ócio proporciona.

\section{Considerações finais}

É incontestável que o trabalho ocupa uma função primordial dentro do ciclo de atividades do homem. Também é bastante plausível considerar que, 
dentro da configuração social em que está inserido, seja bastante difícil retirá-lo da condição de centralidade das ações humanas.

Contudo, também é inegável que essa sociedade do trabalho trouxe inúmeros problemas, principalmente no que diz respeito ao grau de satisfação da grande massa de trabalhadores, que, a cada dia, veem o sentido de suas atividades esvair-se nas funções que ocupa.

Logo, pensar um modelo social centrado no ócio é algo pertinente dentro das condições opressoras que o trabalho impõe na era capitalista, pois, ainda que seja irrealizável, esta sociedade do lazer aparece como alternativa à lógica escravista do capital.

Assim, a mensagem do texto de Russell parece clara. Ou mudam-se os paradigmas, ou a humanidade caminhará para um profundo vazio. Se não for possível dar ao ócio uma importância maior na contemporaneidade, então que o trabalho seja restituído em seu significado. Porém, deve-se lembrar que ambos os modelos não são necessariamente excludentes, e uma solução conciliadora entre eles pode ser encontrada. Neste caso, o que importa é que as atividades fujam à ordem nociva do capitalismo, que transforma ambos os paradigmas em atividades passivas, mecanizadas, desprovidas de qualquer função criadora. Desse modo, a satisfação dos trabalhadores com seu ofício estaria garantida, bem como as diversas criações que só são possíveis mediante a boa utilização do tempo livre.

\section{Referências}

ADORNO, Theodor W. Indústria Cultural e Sociedade. São Paulo: Paz e Terra, 2002.

MILLS, Wright. O trabalho. In: A nova classe média (White Collar). IIII parte. Cap. 10. Rio de Janeiro: Zahar Editores, 1969.

RUSSELL, Bertrand. Elogio ao ócio. Rio de Janeiro: Sextante, 2002.

WEBBER, Max. A ética protestante e o espirito do capitalismo. São Paulo: Pioneira, 1996. 